\title{
Are more competent workers more satisfied?
}

\author{
Citation for published version (APA):
}

de Grip, A., Sieben, I. J. P., \& Stevens, F. C. (2009). Are more competent workers more satisfied? Labour - Review of Labour Economics and Industrial Relations, 23(4), 589-607. https://doi.org/10.1111/J.14679914.2009.00463.X

\section{Document status and date:}

Published: 01/01/2009

DOI:

10.1111/J.1467-9914.2009.00463.X

Document Version:

Publisher's PDF, also known as Version of record

\section{Document license:}

Taverne

\section{Please check the document version of this publication:}

- A submitted manuscript is the version of the article upon submission and before peer-review. There can be important differences between the submitted version and the official published version of record.

People interested in the research are advised to contact the author for the final version of the publication, or visit the DOI to the publisher's website.

- The final author version and the galley proof are versions of the publication after peer review.

- The final published version features the final layout of the paper including the volume, issue and page numbers.

Link to publication

\footnotetext{
General rights rights.

- You may freely distribute the URL identifying the publication in the public portal. please follow below link for the End User Agreement:

www.umlib.nl/taverne-license

Take down policy

If you believe that this document breaches copyright please contact us at:

repository@maastrichtuniversity.nl

providing details and we will investigate your claim.
}

Copyright and moral rights for the publications made accessible in the public portal are retained by the authors and/or other copyright owners and it is a condition of accessing publications that users recognise and abide by the legal requirements associated with these

- Users may download and print one copy of any publication from the public portal for the purpose of private study or research.

- You may not further distribute the material or use it for any profit-making activity or commercial gain

If the publication is distributed under the terms of Article $25 \mathrm{fa}$ of the Dutch Copyright Act, indicated by the "Taverne" license above, 


\section{Are More Competent Workers More Satisfied?}

\section{Andries de Grip — Inge Sieben — Fred Stevens}

Abstract. In this paper, we analyse the relationship between workers' competencies and their job satisfaction in the context of dual (i.e. vocational versus communicative) skill demands. We analyse the effects of workers' competencies on their overall, intrinsic, and extrinsic job satisfaction. We focus on pharmacy assistants who need both pharmaceutical and communicative competencies in their work. Results from a linked employer-employee survey show that assistants with more communicative competencies are more satisfied with their job, whereas assistants with more pharmaceutical competencies are not more satisfied than the less competent assistants. In addition, workers who perform tasks below their level of competence are more dissatisfied with both their remuneration and career prospects and the content of their job as such, than were other workers. Our results indicate that the demand shift from vocational towards communication skills, which occurs in many professions, can affect the job satisfaction of the most competent workers.

\section{Introduction}

Workers' job satisfaction is highly important for the success and survival of firms. Low job satisfaction is associated with low performance, limited service quality, and reduced customer satisfaction (Batt and Moynihan, 2002). Moreover, low job satisfaction can cause health complaints (Waddell, 2004), and a higher staff turnover (e.g. Shields and Ward, 2001), creating substantial financial, social, and psychological costs for workers, organizations, and society (Glisson and Durick, 1988).

Andries de Grip (author for correspondence), Research Centre for Education and the Labour Market (ROA), Maastricht University PO Box 616, 6200 MD Maastricht, the Netherlands. E-mail: a.degrip@maastrichtuniversity.nl — Inge Sieben, Department of Sociology, Tilburg University — Fred Stevens, Faculty of Health, Medicine and Life Sciences, Maastricht University.

The authors thank Ben Kriechel, Jan Sauermann and Jasper Van Loo for their helpful comments on earlier drafts of this paper. 
Although predictors of job satisfaction are well documented, to date little is known about the impact of workers' professional competencies. Workers' competencies may have both negative and positive effects (e.g. Gordon and Arvey, 1975). Adequate competencies are considered essential to a good job performance, which is conducive to higher satisfaction (Ganzach, 2003). However, if individuals become over-competent, they may get bored, start complaining, or try to find more demanding work (Clark and Oswald, 1996).

This study focuses on the relationship between competencies and job satisfaction of pharmacy assistants in the Netherlands. We studied this particular occupational group because it operates at the interface of health professional and commercial activities (see Appendix A). Nowadays, many professionals in health service organizations have become 'front line service employees' (McCammon and Griffin, 2000), facing duality in their work and in the competencies needed. Dutch pharmacy assistants are required by law to have graduated from a vocational school for pharmacy assistants. Young people primarily want to become pharmacy assistants because they are interested in the pharmaceutical aspects of this profession. However, pharmacies in the Netherlands are run as commercial businesses, and increasingly more drugs are supplied in ready-to-use formulations by the pharmaceutical industry. Consequently, pharmacy assistants spend little time preparing drugs and medications, and more time interacting with customers and selling drugs at the counter. This requires communication skills rather than pharmaceutical skills. As a result, pharmacy assistants may face a duality in their job and need both professional, pharmaceutical skills and communication to carry out their professional duties. This duality between professional and commercial duties enables us to explore to what extent employees' vocational competencies and communicative competencies contribute to employees' job satisfaction.

In this way, our study builds on the research of Ganzach (2003), who showed that job satisfaction is related to discrepancies between on the job desires and job reality invoked by differences between workers' abilities, and the complexity of their job. We therefore first of all investigate whether job mismatches between pharmacy assistants' specific vocational (pharmaceutical) and more general (communicative) tasks and competencies affect their job satisfaction. In addition, we analyse whether pharmacy assistants who perform tasks below their level of competence are likely to be less satisfied (cf. Allen and Van der Velden, 2001; Glisson and Durick, 
1988), but also whether assistants who perform tasks above their level of competence are less satisfied (cf. Rose, 2003).

Previous research has shown that overall job satisfaction and domain-specific satisfaction may have different predictors (Ganzach, 2003). We therefore first investigate the extent to which professional pharmaceutical and customer-oriented communicative competencies contribute to employees' overall job satisfaction. Then, we study whether competencies are related to employees' intrinsic satisfaction (i.e. satisfaction with respect to quality of work, such as the content of the job and working conditions) and extrinsic job satisfaction (i.e. satisfaction with respect to instrumental, material aspects of employment such as remuneration and career prospects). This distinction is important because a worker's competencies may affect both intrinsic job satisfaction (by means of the match between competencies and the content of the job and the working conditions) and extrinsic job satisfaction (by means of career prospects). Moreover, a lack of intrinsic job satisfaction may be compensated by high extrinsic job satisfaction because of higher wages.

In this paper, we contribute to the job satisfaction literature by showing that the demand shift from vocational towards communication skills, which occurs in many professions, can affect the job satisfaction of professional workers. Compensating wages do not correct for these intrinsic rewards or disadvantages. Moreover, the results of our study shed light on the relationships between vertical mismatches and job satisfaction among workers employed within their own occupational domain.

The remainder of the paper is structured as follows. In Section 2, we discuss the theoretical backgrounds of our hypotheses on the relationships between workers' competencies and job satisfaction. Section 3 describes our data and empirical model. In Section 4, we present our estimation results. Section 5 concludes.

\section{Theoretical backgrounds and hypotheses}

There is ample evidence of a negative relationship between level of education and job satisfaction (Ganzach, 2003; Sloane and Williams, 1996). The likelihood of apathy and demoralization increases when well-qualified individuals work below their level of competence, have too many routine activities, or loose their professional autonomy vis-à-vis the employing organization (Hochschild, 
1983). Employees' job satisfaction further depends on the match between job characteristics on the one hand, and prospects and aspirations on the other (Ganzach, 2003). For example, Hersch (1991) found that workers overqualified for their job had a lower job satisfaction, possibly because better-qualified workers have higher aspirations. However, Groot and Maassen van den Brink (1999) did not find this relationship for older workers.

Lachman and Aranya (1986) showed that job satisfaction is related to employees' occupational and professional commitment and to the way in which workers' expectations are met by the employing organization (cf. Yousef, 1998). Unambiguous responsibilities concerning tasks to be completed and the possibilities to use a broad range of competencies may be conducive to job satisfaction (Glisson and Durick, 1988).

Potential differences between job requirements and employee competencies can be subdivided into horizontal and vertical mismatches (Di Pietro and Urwin, 2006). Horizontal mismatches apply to the distinction between pharmaceutical and communicative tasks and competencies. On average, Dutch pharmacy assistants spend about 54 per cent of their working time on tasks that are primarily related to communicative competencies (counter contacts and dispensing medicine) and 39 per cent on tasks that demand pharmaceutical competencies (ordering, preparing, and monitoring medicines). Because current duties of pharmacy assistants are more dependent on their communicative skills, rather than pharmaceutical skills, pharmacy assistants may become discouraged in their aspirations and professional commitment. This will particularly hold for those assistants who are most competent in these professional competencies (cf. Ganzach, 2003). Therefore, we expect that assistants who are more competent in their pharmaceutical tasks will be less satisfied with their job than assistants with less pharmaceutical competencies. Assistants with better communicative skills will however be more satisfied with their job, because they have ample opportunities to exploit their excellence. Thus, we propose the following hypothesis on horizontal mismatches.

Hypothesis 1a: Pharmacy assistants with more pharmaceutical competencies will be less satisfied with their job than those with less pharmaceutical competencies.

Hypothesis 1b: Pharmacy assistants with more communicative competencies will be more satisfied than those with less communicative competencies. 
Vertical mismatches refer to the match between perceived complexity of tasks and level of competence. Locke (1976) argues that there is a concave relationship between mental challenge (complexity, autonomy, the opportunities to use abilities and to learn new ones, responsibility, etc. - see Clark, 1996) and job satisfaction: too much mental challenge as well as too little could lead to dissatisfaction. Pharmacy assistants thus may become dissatisfied if their jobs are less challenging, or if they have to perform tasks that are above their level of competence. We propose the following hypothesis.

Hypothesis 2: Pharmacy assistants performing tasks at their level of competence will be more satisfied with their job than assistants performing tasks below or above their level of competence.

Overall job satisfaction can be broken down into intrinsic and extrinsic job satisfaction. Ganzach (2003) showed that overall job satisfaction is mainly determined by employees' intrinsic motivations. As horizontal and vertical mismatches predominantly refer to the content of the job, we expect that these mismatches will particularly affect pharmacy assistants' intrinsic job satisfaction. We therefore propose the following hypotheses.

Hypothesis 3a: Pharmacy assistants with more pharmaceutical competencies will have a lower intrinsic job satisfaction than those with less pharmaceutical competencies.

Hypothesis 3b: Pharmacy assistants with more communicative competencies will have a higher intrinsic job satisfaction than those with less communicative competencies.

Hypothesis 4: Pharmacy assistants performing tasks at their level of competence will have a higher intrinsic job satisfaction than assistants performing tasks below or above their level of competence.

The situation is more complex regarding extrinsic job satisfaction. When there is a horizontal mismatch between pharmacy assistants' competencies and job requirements, higher salary may compensate for the lack of intrinsic job satisfaction, as is reflected in Adam Smith's (1776) notion of 'compensation wages'. However, this argument is not valid when a higher level of pharmaceutical competencies does not contribute to the performance of the pharmacy. As this is the case in the Dutch pharmacies, which are run as commercial businesses delivering predominantly prefab drugs, we expect that the remuneration of employees with more pharmaceutical competencies will not compensate for the lack of intrinsic job 
satisfaction. Moreover, there is no need to increase the wages of assistants with more communicative competencies, as these assistants will be rewarded by a higher intrinsic job satisfaction.

However, vertical skill mismatches are expected to affect employees' extrinsic job satisfaction. When pharmacy assistants perform tasks below their level of competence, they may also be less satisfied with their rewards and career prospects, as these will, in general, be quite low (cf. Rose, 2003). When they perform tasks above their level of competence they will probably be better rewarded. In the latter case, one would expect that assistants' extrinsic job satisfaction would be higher. Therefore, we propose the following two hypotheses on extrinsic job satisfaction.

Hypothesis 5: Pharmacy assistants' level of pharmaceutical or communicative competencies will not affect their extrinsic job satisfaction.

Hypothesis 6: Pharmacy assistants who perform tasks below their level of competence will have a lower extrinsic job satisfaction, whereas assistants performing tasks above their level of competence will have a higher extrinsic job satisfaction than those with a job that matches their level of competence.

\section{Data and empirical model}

\subsection{Data}

To test our hypotheses, we used data from an employee survey among pharmacy assistants, held in November and December 2001. The survey was sent to a random sample of pharmacy assistants working in Dutch pharmacies. In total, 3,229 assistants returned the written questionnaire (response rate 54 per cent). The data were matched with organizational information obtained from an employer survey among Dutch pharmacists held in the same period (response rate 42 per cent) and with administrative data on workforce and drug prescriptions. As the employee survey and the employer survey do not perfectly match, combining the three data sources leads to a linked data set on 1,056 pharmacy assistants working in 388 pharmacies. Because of partial non-response on important variables, we included 847 assistants in our analyses. These selections do not seem to lead to major biases in our dependent and independent variables. ${ }^{1}$ It should, however, be noted that 
in the Netherlands, the occupation of pharmacy assistants is highly female-dominated: less than 1 per cent of the Dutch assistants is male. This means that all surveyed assistants are women. (The only two male pharmacy assistants in the survey were not included in our analyses).

\subsection{Measures of job satisfaction}

Like in other studies on job satisfaction (e.g. Clark, 1996; Ganzach, 2003), we used three subjective measures of job satisfaction: overall job satisfaction, intrinsic job satisfaction, and extrinsic job satisfaction. Overall job satisfaction was assessed using a singleitem measure that implicitly weights a worker's satisfaction on various aspects of the job. We asked assistants: 'Overall, how satisfied are you with your present job?' (answer categories: 'very satisfied', 'satisfied', 'not very satisfied', and 'not satisfied at all'). As only a few pharmacy assistants report being 'not satisfied at all' (see Table B1), we combined this category with the category of being 'not very satisfied'. This implies that the dependent variable has three categories: 'not satisfied', 'satisfied', and 'very satisfied'.

To obtain information about intrinsic and extrinsic job satisfaction, assistants were asked to rate their satisfaction with several job facets, again on a four-point scale with the same answer categories as for overall job satisfaction. An exploratory factor analysis showed two dimensions, which we labeled as intrinsic and extrinsic job satisfaction. Intrinsic job satisfaction consists of satisfaction with (1) work content; (2) work autonomy; (3) work hours; (4) work pressure; (5) safety at work; (6) work atmosphere; and (7) pharmacy management. Cronbach's alpha of this seven item scale is 0.74 . Extrinsic job satisfaction is indicated by satisfaction with (1) wage level; and (2) career prospects; the correlation coefficient between these two items is 0.54. Items and descriptive statistics of overall, intrinsic, and extrinsic job satisfaction are given in Appendix B (Table B1).

\subsection{Measures of competencies}

Pharmacy assistants were asked to rate their competencies on a scale varying between 1 (low score) and 10 (high score). These scores refer to the 10-point scales common in Dutch education, in which a score of 6 is a passing grade. Pharmaceutical competencies were measured by rating (1) knowledge of medicines; (2) knowledge 
of syndromes; (3) skills on dispensing medicines; and (4) preparing medicines. Cronbach's alpha of this four-item scale is 0.70 . Communicative competencies are indicated by (1) communication skills; and (2) communication with colleagues. The correlation coefficient between these two items is 0.60 . Table B2 in Appendix B gives an overview of all items and their descriptives. It should be noted that assistants' pharmaceutical and communicative competencies are self-assessed and therefore subjective. Table B2, however, shows that competency scores assessed by the assistants themselves do not differ that much from overall firm-level scores given by their employers (the pharmacists), although some differences are statistically significant. Self-assessment of assistants' competencies thus seems to be biased by problems of social desirability to a small extent only.

In addition to horizontal mismatches, vertical mismatches imply that pharmacy assistants perform tasks above or below their level of competence. We asked assistants to indicate whether they performed tasks that strictly speaking are not part of their job description. Pharmaceutical tasks of the pharmacist requiring more advanced pharmaceutical expertise as well as management tasks are considered to be tasks that are above the assistants' competence level, whereas tasks of other pharmacy employees such as cleaning are considered to be below their level of competence. Assistants who only perform tasks that are part of their job description are regarded as performing tasks at their level of competence.

\subsection{Controls: personal, work, and organizational characteristics}

Personal, work, and organizational characteristics were included as control variables in the analyses (cf. Ganzach, 2003; Hunt and Saul, 1975). Work experience was measured in years of employment as a pharmacy assistant. Permanent contract is a dichotomous variable indicating whether or not the assistant had a permanent contract. Employment status (full-time versus part-time) was assessed in terms of hours worked per week. Income was computed as the gross monthly salary in euros when working full-time (i.e. 36 hours a week). ${ }^{2}$ Poor working conditions were assessed by asking respondents whether they experienced 'regularly', 'sometimes', or 'never' (1) high work pressure; (2) physical strain; (3) mental strain; (4) poor physical work conditions; and (5) monotonous work. Cronbach's alpha of this five-item scale is 0.56. Organizational variables included pharmacy size, technological change, and organ- 
izational change. Pharmacy size was categorized in four classes based on the number of prescription lines delivered in a year: small (less than 60,000 prescriptions a year), middle $(60,000-80,000)$, large $(80,000-100,000)$, and very large (more than 100,000 prescription lines a year). Information on the number of prescription lines delivered to clients was retrieved from administrative data. It should be noted that the number of prescription lines is an important indicator of pharmacy sales. In 2001, pharmacies received $€ 5.67$ per prescription line from the government.

Technological change was indicated by a positive answer on the question whether a new computer system had been introduced in the past year. Organizational change was measured by the occurrence of a reorganization, merger, or cooperation between pharmacies in the past year.

\subsection{Empirical model}

We estimated ordered probit models for overall job satisfaction and intrinsic and extrinsic job satisfaction. In our ordered probit models, the discrete but ordinal nature of job satisfaction was modeled by denoting three job satisfaction outcomes $\left(\gamma_{i}=0\right.$ 'not satisfied', $\gamma_{i}=1$ 'satisfied', and $\gamma_{i}=2$ 'very satisfied') for individual $i$. This lead to the following estimated model:

$$
\gamma_{i}^{*}=\beta_{\mathrm{pc}} x_{\mathrm{pc}}+\beta_{\mathrm{cc}} x_{\mathrm{cc}}+\beta_{\mathrm{tb}} x_{\mathrm{tb}}+\beta_{\mathrm{ta}} x_{\mathrm{ta}}+\beta_{i} x_{i}+u_{i}
$$

where $\gamma_{i}^{*}$ is the unobserved job satisfaction outcome, $x_{\mathrm{pc}}$ the assistant's pharmaceutical competencies, $x_{\mathrm{cc}}$ the assistant's communicative competencies, $x_{\mathrm{tb}}$ performing tasks below the level of competence, $x_{\text {ta }}$ performing tasks above the level of competence, $x_{i}$ a vector of control variables described above, $\beta_{\mathrm{pc}}, \beta_{\mathrm{cc}}, \beta_{\mathrm{tb}}, \beta_{\mathrm{ta}}$, and $\beta_{i}$ vectors of parameters to estimate, and $u_{i}$ the error term. As in some pharmacies, we have data on more than one assistant, we correct the standard errors for clustering at pharmacies.

\section{Estimation results}

\subsection{Descriptive statistics}

Most pharmacy assistants were satisfied with their job (see Table 1). In line with observations on workers in general (Clark, 1996), assistants were more satisfied with job content and working 
Table 1. Descriptive statistics

\begin{tabular}{|c|c|c|}
\hline & Mean & $\begin{array}{l}\text { Standard } \\
\text { deviation }\end{array}$ \\
\hline \multicolumn{3}{|l|}{ Job satisfaction } \\
\hline Overall job satisfaction (1-4) & 3.17 & 0.64 \\
\hline Intrinsic job satisfaction $(1-4)$ & 3.01 & 0.46 \\
\hline Extrinsic job satisfaction $(1-4)$ & 2.53 & 0.68 \\
\hline \multicolumn{3}{|l|}{ Competencies } \\
\hline Pharmaceutical competencies (1-10) & 7.30 & 0.74 \\
\hline Communicative competencies (1-10) & 7.84 & 0.67 \\
\hline \multicolumn{3}{|l|}{ Performing tasks below or above level of competence } \\
\hline Tasks below level of competence (yes/no) & 0.16 & \\
\hline Tasks above level of competence (yes/no) & 0.15 & \\
\hline \multicolumn{3}{|l|}{ Personal and work characteristics } \\
\hline Work experience as pharmacy assistant (in years) & 13.47 & 8.52 \\
\hline Permanent contract (yes/no) & 0.96 & \\
\hline Working hours per week & 26.66 & 8.50 \\
\hline Monthly income $(\times € 1,000)$ & 1.80 & 0.31 \\
\hline Poor working conditions (yes/no) & 0.22 & \\
\hline \multicolumn{3}{|l|}{ Organizational characteristics } \\
\hline \multicolumn{3}{|l|}{ Firm size } \\
\hline Small pharmacy (yes/no) & 0.26 & \\
\hline Intermediate pharmacy (yes/no) & 0.33 & \\
\hline Large pharmacy (yes/no) & 0.24 & \\
\hline Very large pharmacy (yes/no) & 0.17 & \\
\hline Technological change in past year (yes/no) & 0.17 & \\
\hline Organizational change in past year (yes/no) & 0.53 & \\
\hline
\end{tabular}

conditions (intrinsic job satisfaction) than with remuneration and career prospects (extrinsic job satisfaction). ${ }^{3}$ Assistants were more critical of their pharmaceutical skills than of their communication skills, awarding these skills scores of 7.30 and 7.84 on a 10-point scale, respectively. Pearson correlation between both competencies was 0.41 , reflecting that these competencies are not completely overlapping.

Sixteen per cent of the pharmacy assistants performed tasks below their level of competence, and 15 per cent tasks above their level of competence. Analysis of competencies and task performance suggested that pharmaceutical competencies, more than communicative competencies, were associated with performing tasks both above and below the assistants' level of competence.

The respondents had, on average, 13 years of work experience as a pharmacy assistant: 8 years in the present job and 5 years 
elsewhere. Nearly all assistants had permanent positions. Pharmacy assistant pay scales were based on the salary scales defined in the collective bargaining agreement for Dutch pharmacies. The average gross monthly income was $€ 1,800$ when working full-time (i.e. 36 hours per week); however, most assistants worked part-time (mean 27 hours per week). Twenty-two per cent of the respondents reported poor working conditions, such as regularly working under high time pressure, or doing physically or mentally strenuous work. Twenty-six per cent of the respondents worked in a small pharmacy and 17 per cent in a very large pharmacy. Only 17 per cent of the respondents reported technological changes in the pharmacy (introduction of a new computer system in the past year), whereas organizational changes were much more common, being reported by more than 50 per cent of the respondents.

\subsection{Overall job satisfaction}

The second column of Table 2 shows the estimation results of the ordered probit analysis on overall job satisfaction. This analysis reveals that pharmaceutical competencies are negatively associated with job satisfaction, whereas communication competencies are positively associated with overall job satisfaction. However, only the latter is statistically significant. This supports Hypothesis $1 \mathrm{~b}$ that pharmacy assistants with more communicative competencies are more satisfied than those with less communicative competencies. Overall job satisfaction is not significantly correlated with the performance of tasks below or above the assistant's level of competence. Our second hypothesis, predicting higher levels of job satisfaction for assistants who perform tasks at their level of competence than for assistants who perform tasks below or above their level of competence, therefore, has to be rejected. In this respect, it could be interesting to look at interactions between assistants' competencies and their task levels. However, estimates including these interaction terms did not provide any additional significant results.

Not surprisingly, overall job satisfaction is negatively correlated with poor working conditions (cf. Losocco and Spitze, 1990). In addition, assistants working in small pharmacies are less satisfied with their job. At first glance, this seems to be in contrast to earlier findings that the most satisfied workers are to be found at smaller establishments (Clark, 1996), but is should be kept in mind that Dutch pharmacies are very small in size compared with other firms. Assistants who are employed in pharmacies that experienced 
Table 2. Results of ordered probit regression analyses on overall, intrinsic, and extrinsic job satisfaction $(n=847)$

Overall job Intrinsic job Extrinsic job satisfaction satisfaction satisfaction

\begin{tabular}{lccc}
\hline Competencies & & & \\
Pharmaceutical competencies & -0.109 & 0.069 & -0.026 \\
& $(0.071)$ & $(0.081)$ & $(0.067)$ \\
Communicative competencies & $0.249^{* * *}$ & $0.250^{* *}$ & -0.010 \\
& $(0.073)$ & $(0.075)$ & $(0.077)$ \\
& & \\
Performing tasks below or above level of competence & & \\
Tasks below level of competence & -0.147 & $-0.193^{*}$ & $-0.212^{*}$ \\
& $(0.107)$ & $(0.115)$ & $(0.114)$ \\
Tasks above level of competence & -0.128 & -0.030 & 0.191 \\
& $(0.124)$ & $(0.151)$ & $(0.125)$ \\
Personal and work characteristics & & & \\
Work experience as pharmacy assistant & -0.015 & -0.033 & $-0.061^{* * *}$ \\
& $(0.021)$ & $(0.025)$ & $(0.021)$ \\
Work experience as pharmacy & 0.0004 & 0.001 & $0.001^{* *}$ \\
assistant squared & $(0.0005)$ & $(0.001)$ & $(0.001)$ \\
Permanent contract & -0.030 & 0.225 & -0.215 \\
& $(0.227)$ & $(0.199)$ & $(0.198)$ \\
Working hours per week & 0.002 & -0.007 & $-0.017^{* * *}$ \\
& $(0.006)$ & $(0.007)$ & $(0.005)$ \\
Monthly income & 0.040 & 0.021 & $0.392^{* *}$ \\
& $(0.186)$ & $(0.266)$ & $(0.192)$ \\
Poor working conditions & $-1.969 * *$ & $-2.287^{* * *}$ & $-1.431^{* * *}$ \\
& $(0.187)$ & $(0.220)$ & $(0.200)$
\end{tabular}

Organizational characteristics

Firm size

Small pharmacy

Intermediate pharmacy

Reference Reference Reference

Large pharmacy

$\begin{array}{lll}0.210 * & 0.021 & 0.036\end{array}$

$(0.119) \quad(0.132) \quad(0.111)$

Very large pharmacy

$\begin{array}{lll}0.278 * * & 0.197 & 0.070\end{array}$

$\begin{array}{lll}(0.131) & (0.127) \quad(0.135)\end{array}$

$\begin{array}{ccc}0.296^{*} & 0.269 & 0.310 \\ (0.150) & (0.154) & (0.135)\end{array}$

Technological change in past year

$0.0319-0.059$

0.165

Organizational change in past year

$(0.112)$

$(0.137)$

$(0.113)$

$-0.238 * * * \quad-0.077 \quad 0.042$

$\begin{array}{lll}(0.090) & (0.104) \quad(0.091)\end{array}$

Constant 1

$-0.576$

0.295

$-1.050$

Constant 2

(0.664)

(0.699)

(0.642)

$1.390 * *$

$3.283 * * *$

0.862

(0.665)

(0.720)

$(0.642)$

Nagelkerke pseudo- $R^{2}$
0.101
0.133

0.007

$* \mathrm{p}<0.10 ; * * \mathrm{p}<0.05 ; * * * \mathrm{p}<0.01$. 
organizational change during the past year are also less satisfied with their job (cf. Bryson et al., 2009; Handel, 2005).

\subsection{Intrinsic and extrinsic job satisfaction}

The third and fourth columns of Table 2 show the estimates of the analyses on intrinsic and extrinsic job satisfaction. The results reveal that assistants' communicative competencies are positively associated with intrinsic job satisfaction (i.e. job content and related conditions), which confirms part of the third hypothesis that assistants with more communicative competencies have higher intrinsic job satisfaction than those with less communicative competencies. In addition, assistants' level of communicative competencies is not correlated with extrinsic job satisfaction (remuneration and career prospects), nor is assistants' level of pharmaceutical competencies. This supports our fifth hypothesis that both types of competencies do not affect extrinsic job satisfaction. However, in conflict with the first part of the third hypothesis predicting that pharmacy assistants with more pharmaceutical competencies have lower intrinsic job satisfaction than those with less pharmaceutical competencies, assistants' levels of pharmaceutical competencies are not significantly correlated with intrinsic job satisfaction. Finally, performing tasks below one's level of competence is negatively associated with both intrinsic and extrinsic job satisfaction, which is consistent with Hypotheses 4 and 6. However, these relationships are only weakly significant. We find no support for the other predictions of Hypothesis 6 that assistants performing tasks above their level of competence will have a higher extrinsic job satisfaction than those with a job that matches their level of competence. Moreover, we do not observe a positive relationship between performing tasks at the level of competence and intrinsic job satisfaction, as was expected in Hypothesis 4.

The last two columns of Table 2 also show that several personal and work characteristics are associated with intrinsic and extrinsic job satisfaction. Assistants with more work experience report less satisfaction with remuneration and career prospects, although this effect levels off in time, as indicated by the square term. Monthly income is positively correlated with assistants' satisfaction with wages and career prospects. In addition, working fewer hours is associated with less extrinsic job satisfaction. Poor working conditions have a strong negative effect on both intrinsic and extrinsic job satisfaction. Of the organizational characteristics, only the size 
of the pharmacy is associated with job satisfaction: respondents working in large pharmacies report more extrinsic job satisfaction.

\section{Conclusions}

In this study, we analysed the effects of pharmacy assistants' competencies and job content on job satisfaction. In line with our first hypothesis regarding horizontal mismatches, we found that pharmacy assistants with higher levels of communicative competencies had higher overall satisfaction scores. In particular, they were more satisfied with the intrinsic qualities of their work. Pharmaceutical competencies, on the other hand, did not have a significant effect on overall job satisfaction. These results clearly reflect the shift in impact from pharmaceutical tasks to communicative tasks in the work of pharmacy assistants. Communicative competencies thus appear to be more important to job satisfaction than specific vocational competencies.

The 'vertical mismatches' hypothesis that pharmacy assistants who performed tasks at their level of competence would have a higher overall job satisfaction than assistants who performed tasks below or above their level of competence was not confirmed. In the separate regressions on intrinsic and extrinsic job satisfaction, we do however find weakly significant relationships between performing tasks below assistants' level of competence and their job satisfaction. As we expected, neither communicative nor pharmaceutical competencies are associated with extrinsic job satisfaction. This indicates that assistants' expectations of remuneration and career prospects are in line with their competencies. Our estimation results might, however, be affected by a selection effect when assistants whose competences have the worst match with their job demands more often quit the profession. In that case, we would probably underestimate the negative effect of pharmaceutical competencies on pharmacy assistants' job satisfaction.

Our results also show that 'quality of working life' has a major role in predicting job satisfaction. Poor working conditions, work experience, working hours, monthly income, and pharmacy size primarily influenced assistants' extrinsic job satisfaction. Moreover, overall job satisfaction was negatively affected by changes in the organization of the pharmacy. This shows that pharmacy assistants' job satisfaction is affected by discontinuities in their job content due to changes in the organization of their work but 
not by technological changes, because the introduction of a new computer system or software programs did not affect assistants' job satisfaction.

Comparing the results of different satisfaction models (i.e. overall, intrinsic, and extrinsic job satisfaction), we observed that intrinsic job satisfaction was similar to overall job satisfaction in terms of the effect of individual competencies. Consequently, our study confirms the conclusion of Groot and Maassen van den Brink (1999) and Ganzach (2003) that people are primed to think about intrinsic rather than extrinsic sources of satisfaction. This means that although higher wages positively affect assistants' extrinsic job satisfaction, they do not compensate for the negative effects of employees' pharmaceutical competencies, nor do they induce a 'wage penalty' for the positive effect of their communicative competencies on their intrinsic job satisfaction. This contradicts Adam Smith's (1776) theory of 'compensating wages', as this theory would imply that (lower) intrinsic job satisfaction would be substituted by (higher) extrinsic job satisfaction. ${ }^{4}$

The occupation of pharmacy assistant in the Netherlands offered an interesting opportunity to analyse whether workers' job satisfaction is related to the duality of skills demanded in the job. This increasing duality is a recent trend in many occupations in which interactions with customers become more important, and in which traditionally required vocational skills become less important (cf. Gallie et al., 2004). In this respect, our findings might signal a short-run phenomenon, as youngsters will gradually learn that the character of pharmacy assistant jobs has changed. However, this also requires that vocational schools for pharmacy assistants should strengthen their focus on communication skills instead of pharmaceutical skills in their curriculum.

Our focus on the impact of the duality of skills demanded in a job on workers job satisfaction is highly relevant for other healthcare occupations (see, for example, Liu et al., 2005), as well as for occupations in different economic sectors (cf. Demoussis and Giannakopoulos, 2007). However, all occupations have specific idiosyncratic characteristics that may affect research outcomes. For example, almost all Dutch pharmacy assistants are women, who might value their work content differently from men (cf. Clark, 1996; Sloane and Williams, 2000). ${ }^{5}$ Therefore, more research focusing on different occupational groups will contribute to our insight into the effects of changing skills demands in the labor market on workers' job satisfaction. 


\section{Appendix A}

In the Netherlands, registered drugs can only be obtained from pharmacies on presentation of a family doctor's prescription. Although Dutch pharmacies are strongly regulated, they are nevertheless truly independent, for-profit firms. About 20 per cent of Dutch pharmacies are part of a (international) wholesaling company. In 2001, the 1,631 pharmacies distributed $€ 3,419$ million worth of drugs (SFK, 2002). In this respect, it should be noted that in the Netherlands, non-registered drugs are usually supplied by commercial drugstores and contribute little to pharmacy sales.

The average pharmacy serves 9,000 patients and has 8.7 fulltime equivalents (FTE) staff: one pharmacist, under whose supervision the drugs are prepared and distributed, 5.8 FTE pharmacy assistants, and about 1.9 FTE other employees (usually cleaning personnel and administrative staff). Overall, Dutch pharmacies employ 12,640 pharmacy assistants (De Grip et al., 2003). It is the pharmacy assistants who usually deliver the drugs and have contacts with the customers.

\section{Appendix B}

Table B1. Pharmacy assistants' overall, intrinsic, and extrinsic job satisfaction

\begin{tabular}{lcccc}
\hline & $\begin{array}{c}\text { Very satisfied } \\
\text { (per cent) }\end{array}$ & $\begin{array}{c}\text { Satisfied } \\
\text { (per cent) }\end{array}$ & $\begin{array}{c}\text { Not very } \\
\text { satisfied } \\
\text { (per cent) }\end{array}$ & $\begin{array}{c}\text { Not satisfied } \\
\text { at all } \\
\text { (per cent) }\end{array}$ \\
\hline Overall job satisfaction & 29.0 & 59.7 & 10.3 & 1.0 \\
Intrinsic job satisfaction & 10.9 & 79.6 & 9.3 & 0.2 \\
Work content & 20.2 & 68.4 & 9.7 & 1.6 \\
Work autonomy & 34.5 & 61.8 & 3.5 & 0.2 \\
Work hours & 28.6 & 65.5 & 5.5 & 0.5 \\
Work pressure & 5.5 & 54.8 & 31.4 & 8.2 \\
Safety at work & 12.8 & 73.1 & 13.0 & 1.0 \\
Work atmosphere & 31.1 & 56.3 & 11.0 & 1.5 \\
Pharmacy management & 14.7 & 53.4 & 23.7 & 8.2 \\
Extrinsic job satisfaction & 4.7 & 49.2 & 40.4 & 5.6 \\
Wage level & 2.9 & 38.3 & 44.5 & 14.3 \\
Career perspectives & 4.2 & 41.7 & 38.6 & 15.5 \\
\hline
\end{tabular}


Table B2. Pharmacy assistants' pharmaceutical and communicative competencies: mean scores (scale 1-10) and standard deviations (SD), assessed by assistants themselves and by their employers (pharmacists)

\begin{tabular}{|c|c|c|c|c|c|}
\hline & \multicolumn{2}{|c|}{$\begin{array}{l}\text { Self-assessment } \\
\text { scores }\end{array}$} & \multicolumn{2}{|c|}{$\begin{array}{l}\text { Employers' } \\
\text { scores }\end{array}$} & \multirow{2}{*}{$\begin{array}{c}\text { Difference } \\
\begin{array}{c}\text { Significance } \\
\text { level }\end{array}\end{array}$} \\
\hline & Mean & SD & Mean & SD & \\
\hline Pharmaceutical competencies & 7.30 & 0.74 & 7.24 & 0.54 & ns \\
\hline Knowledge on medicines & 7.21 & 0.85 & 7.00 & 0.81 & $* * *$ \\
\hline Knowledge on syndromes & 6.77 & 0.91 & 6.69 & 0.92 & ns \\
\hline Dispensing medicines & 7.75 & 0.95 & 7.71 & 0.65 & ns \\
\hline Preparing medicines & 7.46 & 1.34 & 7.58 & 0.72 & $* *$ \\
\hline Communicative competencies & 7.84 & 0.67 & 7.46 & 0.66 & $* * *$ \\
\hline General communication skills & 7.66 & 0.82 & 7.29 & 0.69 & $* * *$ \\
\hline Communication with colleagues & 8.02 & 0.76 & 7.64 & 0.83 & $* * *$ \\
\hline
\end{tabular}

* $P<0.10 ; * * P<0.05 ; * * * P<0.01$.

\section{Notes}

${ }^{1}$ In non-response analyses, we (1) compared assistants who could be matched to information of the pharmacy they work in with assistants with missing pharmacy information who are excluded from our regression analyses; and (2) compared assistants who are included in the regression analyses with assistants with partial non-response. The results of these two non-response analyses showed that the assistants included in our analyses have similar characteristics to those not included. Therefore, it is justified to assume that the selections made do not lead to major biases in our results.

${ }^{2}$ Collective bargaining only determines three salary scales in which several wage steps are distinguished. This gives the employer ample opportunities to reward pharmacy assistants with better competencies.

${ }^{3}$ The mean scores on overall job satisfaction, intrinsic job satisfaction, and extrinsic job satisfaction are significantly different from each other at $P<0.001$ level.

${ }^{4} \mathrm{We}$ also tested this by comparing the estimation results presented in Table 2 with the estimation results of regression on overall, intrinsic, and extrinsic job satisfaction without the monthly income variable. This comparison shows that including or excluding the monthly income variable does not affect the coefficients of the two variables on workers' competencies (estimation results can be obtained from the corresponding author on request).

${ }^{5}$ However, Sousa-Poza and Sousa-Poza (2000) found that this is mainly an Anglo- Saxon phenomenon. 


\section{References}

Allen J. and Van der Velden R. (2001) 'Educational Mismatches versus Skills Mismatches: Effects on Wages, Job Satisfaction, and On-the-job-search', Oxford Economic Papers 53: $434-452$.

Batt R. and Moynihan L. (2002) 'The Viability of Alternative Call Centre Production Models', Human Resource Management Journal 12: 14-34.

Bryson A., Barth E. and Dale-Olsen H. (2009) 'How Does Innovation Affect Worker Wellbeing?', Mimeo, National Institute for Economic and Social Research, London.

Clark A. E. (1996) 'Job Satisfaction in Britain', British Journal of Industrial Relations 34: 189-217.

Clark A. E. and Oswald A. J. (1996) 'Satisfaction and Comparison Income', Journal of Public Economics 61: 359-381.

De Grip A., Hensen M. and Sieben I. (2003) De arbeidsmarkt voor apothekersassistenten tot 2010: een toekomstverkenning [The Labour Market for Pharmacist's Assistants till 2010: An Exploration of the Future], Maastricht: ROA.

Demoussis M. and Giannakopoulos N. (2007) 'Exploring Job Satisfaction in Private and Public Employment: Empirical Evidence from Greece', Labour 21: $333-359$.

Di Pietro G. and Urwin P. (2006) 'Education and Skills Mismatch in the Italian Graduate Labour Market', Applied Economics 38: 79-93.

Gallie D., Felstead A. and Green F. (2004) 'Changing Patterns of Task Discretion in Britain', Work, Employment and Society 18: 243-266.

Ganzach Y. (2003) 'Intelligence, Education, and Facets of Job Satisfaction', Work and Occupations 30: 97-122.

Glisson C. and Durick M. (1988) 'Predictors of Job Satisfaction and Organizational Commitment in Human Service Organization', Administrative Science Quarterly 33: 61-81.

Gordon M. E. and Arvey R. D. (1975) 'The Relationship between Education and Satisfaction with Job Content', Academy of Management Journal 18: 888-892.

Groot W. and Maassen van den Brink H. (1999) 'Job Satisfaction of Older Workers', International Journal of Manpower 20: 343-360.

Handel M. J. (2005) 'Trends in Perceived Job Quality, 1989 to 1998', Work and Occupations 32: 66-94.

Hersch J. (1991) 'Education Match and Job Match', Review of Economics and Statistics 73: 140-144.

Hochschild A. R. (1983) The Managed Heart. Commercialization of Human Feeling, Berkeley/Los Angeles, London: University of California Press.

Hunt J. W. and Saul P. N. (1975) 'The Relationship of Age, Tenure, and Job Satisfaction in Males and Females', Academy of Management Journal 18: 690-702.

Lachman R. and Aranya N. (1986) 'Evaluation of Alternative Models of Commitments and Job Attitudes of Professionals', Journal of Occupational Behaviour 7: 227-243.

Liu C.-M. et al. (2005) 'An Analysis of Job Satisfaction among Physician Assistants in Taiwan', Health Policy 73: 66-77. 
Locke E. A. (1976) 'The Nature and Causes of Job Satisfaction' in Dunette M. D. (ed.) Handbook of Industrial and Organizational Psychology, Chicago, IL: Rand McNally: 1297-1350.

Losocco K. A. and Spitze G. (1990) 'Working Conditions, Social Support, and the Well-being of Female and Male Factory Workers', Journal of Health and Social Behavior 31: 313-327.

McCammon H. J. and Griffin L. J. (2000) 'Workers and Their Customers and Clients. An Editorial Introduction', Work and Occupations 27: 278-293.

Rose M. (2003) 'Good Deal, Bad Deal? Job Satisfaction in Occupations', Work, Employment and Society 17: 503-530.

SFK (2002) Feiten en cijfers 2002 [Facts and Figures 2002], Den Haag: SFK.

Shields M. and Ward M. (2001) 'Improving Nurse Retention in the National Health Service in England: The Impact of Job Satisfaction on Intentions to Quit', Journal of Health Economics 20: 677-701.

Sloane P. and Williams H. (1996) 'Are "Overpaid” Workers Really Unhappy?', Labour 10: 3-15.

Sloane P. and Williams H. (2000) 'Job Satisfaction, Comparison Earnings and Gender', Labour 14: 473-502.

Smith A. (1776) The Wealth of Nations, Edinburgh: Adam and Ch. Black.

Sousa-Poza A. and Sousa-Poza A. A. (2000) 'Taking Another Look at the Gender/ Job-satisfaction Paradox', Kyklos 53: 135-152.

Waddell G. (2004) The Back Pain Revolution, Edinburgh, London: Churchill Livingstone.

Yousef D. A. (1998) 'Satisfaction with Job Security as a Predictor of Organizational Commitment and Job Performance in a Multicultural Environment', International Journal of Manpower 19: 184-194. 